\title{
EVALUATING THE EFFECTIVENESS OF EXPOSURE TO COUNTERSTEREOTYPIC FATHERS ON REDUCING IMPLICIT FATHER AND MOTHER STEREOTYPES IN JAPAN
}

\author{
Mizuka Ohtaka \\ Department of Politics and Public Administration, Faculty of Law, Yamanashi Gakuin University (Japan)
}

\begin{abstract}
Lai, et al. (2014) compared 17 intervention effects on implicit racial prejudice and concluded that exposure to counterstereotypic exemplars was most effective. Therefore, this study examined whether exposure to counterstereotypic fathers can reduce the implicit stereotype that 'fathers should work outside the home and mothers should keep the house'. The Go/No-Go Association Task (GNAT, Nosek \& Banaji, $2001)$ was conducted among undergraduates $(N=44 ;$ Men $=26$, Women $=18)$, whose mean age was 20.16 years $(S D=1.35)$. The results indicated that, in the control condition, more fathers than mothers implicitly associated with work $(F(1,80)=9.26, p<.01)$, and more mothers implicitly associated with home $(F(1,80)=10.84, p<.01)$; however, such differences were not significant in the counterstereotypic fathers condition. Thus, for men, exposure to counterstereotypic fathers can reduce the implicit father and mother stereotypes. Further research that can generalise the findings must be conducted.
\end{abstract}

Keywords: Stereotype, father, mother.

\section{Introduction}

Ohtaka (2019) investigated the difference between the parent stereotypes and the overall gender stereotypes in Japan and found that the content of the former differed from that of the latter. Ohtaka (2019) suggested that Japanese have the idea that 'fathers (rather than men) should work outside the home, and mothers (rather than women) should keep the house'. Therefore, to solve gender inequality in Japan, the efficient approach may be to focus on parent stereotypes rather than the overall gender stereotypes.

Meanwhile, Park, Smith, and Correll (2010) examined not explicit but implicit stereotypes and showed that fathers are strongly associated with professional images and mothers, with childcare images. Moreover, explicit prejudice predicts deliberative behaviour, whereas implicit prejudice predicts spontaneous behaviour (Dovidio, Kawakami, Johnson, Johnson, \& Howard, 1997). Similarly, explicit prejudice predicts verbal behaviour, whereas implicit prejudice predicts non-verbal behaviour (Dovidio, Kawakami, \& Gaertner, 2002). Especially, gender stereotypes are not explicitly expressed by social desirability; they persist implicitly (Blair \& Banagi, 1996). Thus, this study centred on implicit parent stereotypes and attempted to identify ways of reducing them.

Lai, Marini, Lehr, Cerruti, Shin, Joy-Gaba, Ho, Teachman, Wojcik, Koleva, Frazier, Heiphetz, Chen, Turner, Haidt, Kesebir, Hawkins, Schaefer, Rubichi, Sartori, Dial, Sriram, Banaji, and Nosek (2014) meta-analysed 17 intervention effects on implicit racial prejudice and concluded that exposure to counterstereotypic exemplars is the most efficient. Therefore, this study investigated whether exposure to counterstereotypic fathers can reduce the implicit stereotype that 'fathers should work outside the home and mothers should keep the house'.

\section{Methods}

Forty-four undergraduates participated in this study. They were 18 to 25 years old, of both genders, unmarried, born and raised in Japan, and spoke Japanese as their native language. 
The first study was conducted as a study on memory based on Dasgupta and Asgari (2004). Participants were shown pictures and descriptions of either counterstereotypic fathers or flowers. After reading the descriptions, the participants saw the pictures again with an abbreviated correct and incorrect description of each individual (or flower) placed below each picture. They were asked to identify the correct description. This memory test was administered to ensure that the participants had paid attention to the information as well as to strengthen the memory cover story. After identifying the correct description, the participants in the counterstereotypic fathers' condition were asked to rate the extent to which they thought most other fathers could enjoy childrearing as these fathers on a five-point scale ranging from 0 (impossible) to 4 (possible). The participants in the flowers control condition were asked to indicate the flowers they liked most.

In addition, four famous fathers who enjoy childrearing were selected from 'Ikumen (fathers who enjoy childrearing) of the year' prize winners. The pictures were culled, and the descriptions of each individual were created from the internet site of 'Ikumen of the year' (Executive committee of ikumen of the year, 2020). Meanwhile, four flowers were collected for the control condition. The pictures were culled, and the descriptions of each flower were created from the internet site of 'gardening for pleasure'.

In the second study, the Go/No-go Association Task (GNAT, Nosek \& Banaji, 2001) was conducted as a study on judgment based on Park, Smith, and Correll (2010). On the computer, the participants were presented with items from a number of different categories and instructed to press a button (go) whenever an item from one of two focal categories (e.g. 'dad' and 'home') appeared and to make no response (no-go) when the item was not from those two categories. Stimuli were presented for a 500-ms response window. Error feedback (X) was provided. Each d' (Green \& Swets, 1966) (where as higher $d$ ' indicates a strong association between two categories) was calculated for four combinations of categories ('father' and 'home', 'mother' and 'home', 'father' and 'work', 'mother' and 'work').

The 'father' $(\mathrm{N}=5)$ and 'mother' $(\mathrm{N}=5)$ words were selected from fathers' and mothers' names called by their children (e.g. 'father', 'dad', and 'papa' / 'mother', 'mom', and 'mama') (Benesse, 2009). The 'home' $(\mathrm{N}=5)$ words were 'cleaning', 'washing', 'housework', 'childrearing', and 'cooking'; the 'work' ( $\mathrm{N}=5$ ) words were 'meeting', 'workplace', 'commuting', 'working', and 'company' (Hanita \& Murata, 2013). Distractor categories were 'surnames' and 'bird names'. The 'surname' $(\mathrm{N}=5)$ words were selected from three-character surnames taken from the most frequently used surnames in Japan (Origin Production Committee, 2020). The 'bird name' $(\mathrm{N}=5)$ words were selected from three-character bird names taken from the most familiar bird names in Japan (Wild Bird Society of Japan, 2020).

Finally, the participants answered self-reported questionnaires on demographic measures on the computer.

\section{Results}

\subsection{Respondents}

The participants' mean age was $20.16(S D=1.35)$ years. The participants were 26 men and 18 women. Twenty-three (13 men and 10 women) participants were randomly assigned to the counterstereotypic fathers' condition, and 21 (13 men and 8 women) to the flowers control condition.

\subsection{Analysis of variance}

The data were analysed using four-way analysis of variance. The analysis design used four independent variables: the counterstereotypic fathers condition or the flowers control condition (between factor) [condition], being man or woman (between factor) [participants' gender], the category of either fathers or mothers (within factor) [parents' gender], and the category of either home or work (within factor) [domain]. Dependent variables were the $d$ 's for the four combinations of categories ('father' and 'home', 'mother' and 'home', 'father' and 'work', 'mother' and 'work').

First, the four-way interaction effect of [condition] $\times[$ participants' gender] $\times[$ parents' gender] $\times$ [domain] was significant $(F(1,40)=4.81, p<.05)$.

Second, the simple three-way interaction effect of [condition] $\times$ [participants' gender] $\times$ [domain] was significant in the fathers category $(F(1,80)=4.26, p<.05)$.

Third, the simple-simple two-way interaction effect of [condition] $\times$ [parents' gender] was significant among men participants in the home category $(F(1,80)=4.97, p<.05)$ and in the work category $(F(1,80)=4.88, p<.05)$. 
Fourth, the simple-simple-simple main effect of [parents' gender] was significant among men participants in the flowers control condition in the home category $(F(1,80)=10.84, p<.01)$. Men participants in the flowers control condition associated mothers $\left(d^{\prime}=3.89\right)$ more strongly with home compared with fathers $\left(d^{\prime}=2.98\right)$. Such significant effect was not found among men participants in the counterstereotypic fathers' condition in the home category. As such, men participants might have associated fathers and mothers equally with home after exposure to counterstereotypic fathers.

The simple-simple-simple main effect of [parents' gender] was significant among men participants in the flowers control condition in the work category $(F(1,80)=9.26, p<.01)$. Men participants in the flowers control condition associated fathers $\left(d^{\prime}=3.59\right)$ more strongly with work compared with mothers $\left(d^{\prime}=2.75\right)$. Such significant effect was not found among men participants in the counterstereotypic fathers' condition in the work category. As such, men participants might have associated fathers and mothers equally with work after exposure to counterstereotypic fathers.

Figure 1. Average d' scores.

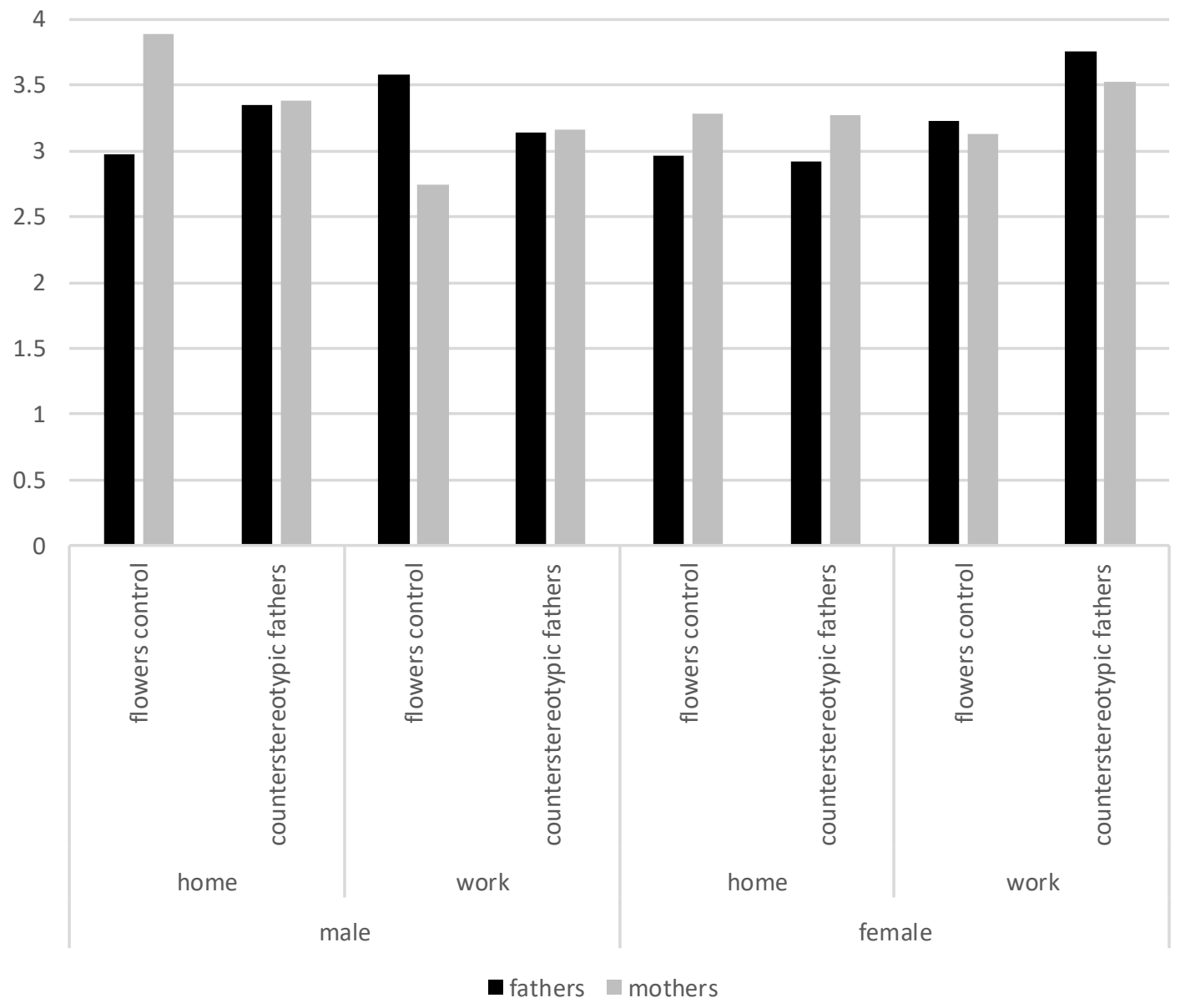

\section{Discussion}

The results imply that exposure to counterstereotypic fathers can reduce the implicit stereotype that 'fathers should work outside the home and mothers should keep the house' among men. In contrast, among women, exposure to counterstereotypic fathers could not reduce the implicit stereotype. In this connection, Dasgupta and Asgari (2004) showed that women who are exposed to counterstereotypic women leaders are less likely to express implicit stereotypic beliefs about women. To reduce implicit stereotypes, an affective measure for men and women is exposure to counterstereotypic men and women, respectively.

Because gender stereotypes vary according to socio-economic factors (Suzuki, 2017), the future study should target not only undergraduates but also older and/or less educated people. It can generalise these findings. 


\section{References}

Benesse. (2020). Names of parent and child. Retrieved from https://benesse.jp/kyouiku/201002/20100225-1.html

Dasgupta, N., \& Asgari, S. (2004). Seeing is believing: Exposure to counterstereotypic women leaders and its effect on the malleability of automatic gender stereotyping. Journal of Experimental Social Psychology, 40(5), 642-658.

Dovidio, J. F., Kawakami, K., \& Gaertner, S. L. (2002). Implicit and explicit prejudice and interracial interaction. Journal of Personality and Social Psychology, 82(1), 62-68.

Dovidio, J. F., Kawakami, K., Johnson, C., Johnson, B., \& Howard, A. (1997). The nature of prejudice: Automatic and controlled processes. Journal of Experimental Social Psychology, 33(5), 510-540.

Executive committee of ikumen of the year. (2020). Ikumen of the year. Retrieved fromhttp://ikumen-ofthe-year.com/index.html

Green, D. M., \& Swets, J. A. (1966). Signal detection theory and psychophysics. New York: Wiley.

Hanita, K., \& Murata, K. (2013). The effect of remembering exemplars of traditional of non-traditional women on the implicit belief about sex-roles. Cognition Studies, 20(3), 307-317.

Lai, C. K., Marini, M., Lehr, S. A., Cerruti, C., Shin, J.-E. L., Joy-Gaba, J. A., Ho, A. K., Teachman, B. A., Wojcik, S. P., Koleva, S. P., Frazier, R. S., Heiphetz, L., Chen, E. E., Turner, R. N., Haidt, J., Kesebir, S., Hawkins, C. B., Schaefer, H. S., Rubichi, S., Sartori, G., Dial, C. M., Sriram, N., Banaji, M. R., \& Nosek, B. A. (2014). Reducing implicit racial preferences: I. A comparative investigation of 17 interventions. Journal of Experimental Psychology: General, 143(4), 1765-1785.

NHK publishing. (2020). Gardening for pleasure. Retrieved from https://www.shuminoengei.jp/?m=pc\&a=page_p_top

Nosek, B. A., \& Banaji, M. R. (2001). The go/no-go association task. Social Cognition, 19(6), 625-664.

Ohtaka, M. (2019). Content of the father and mother stereotypes in Japan: Compared to the overall gender stereotypes. In C. Pracana \& M. Wang (Eds.), Psychology applications \& developments $V$ (pp.181-189). Lisbon: inScience Press.

Origin Production Committee. (2020). Surnames ranking. Retrieved from https://myojiyurai.net/prefectureRanking.htm

Park, B., Smith, J. A., \& Correll, J. (2010). The persistence of implicit behavioural associations for moms and dads. Journal of Experimental Social Psychology, 46(5), 809-815.

Wild Bird Society of Japan. (2020). Bird fan. Retrieved from https://www.birdfan.net/ 